\title{
Determining the Feasibility of Adopting Technological Innovation to Enhance Service Delivery in Selected Johannesburg Health Institutions
}

\author{
Lloyd Uta \\ Department of Marketing, University of the Witwatersrand \\ Email: kudzanai.uta@gmail.com \\ *Norman Chiliya \\ Department of Marketing, University of the Witwatersrand \\ Email: norman.chiliya@wits.ac.za \\ Tinashe Chuchu \\ Department of Marketing, University of the Witwatersrand \\ Email: tinashechuchu@yahoo.com
}

Doi:10.5901/mjss.2014.v5n25p148

\begin{abstract}
South African health institutions, particularly public hospitals are continuously oversubscribed and under-resourced which consequently puts pressure on the service delivery system and negatively affects the service experience of patients. As a way to address this problem, the researchers were looking to establish the feasibility of adopting technological innovation such as Customer Relationship Management (CRM) systems, cloud computing and web-applications in order to help enhance service delivery in Johannesburg health institutions. The researchers conducted a quantitative research and collected data from two public health institutions namely Charlotte Maxeke and Helen Joseph Hospital. An initial pilot study was conducted before the research was extended to a wider sample of 358 respondents. Results show that most patients generally have a positive perception on technology and are likely to consider making use technological-innovation provided they are relatively easy to use, accessible and not too complex. Results also suggest that security is a highly regarded factor that ultimately determines system-usage and technological acceptance. Technological innovations such as CRM systems, may go a long way in enhancing interaction between patients and health institutions which ultimately would result in the creation of more sustainable relationships between patients and health institutions. However in order to ensure that there is wide adoption of technologicalinnovation, it is essential for health institutions to ensure that the new innovations are easy to use and patient information is kept in a secure environment.
\end{abstract}

Keywords: CRM systems, Cloud Computing, Web applications

\section{Introduction and Background to the Study}

The medical health-care in South Africa has been experiencing a number of challenges in trying to operate more effectively and efficiently over the past 15 years (Harrison, 2009). According to Cullinan (2006) 10\% of the people who polled in a research survey indicated that they trusted state hospitals while half said they received poor service from hospitals and were therefore not satisfied with the service delivery. This may have been due to several limiting factors resulting in service delivery within the health sector remaining relatively poor than the health care services of established and developed countries like United States of America. Britain's National Health Service, for example, is recognized as one of the most efficient public health service organizations in the world, and its success is largely due to the adoption of technological innovations (Ramesh, 2011). This research paper establishes the significance of adopting technological innovations such as use of CRMs, cloud-computing and other web-based services in order to enhance service delivery in various hospitals around Johannesburg and whether it is feasible to make use of these innovations.

Performance of most health institutions has been largely affected by the poor adoption of technological innovations. This has often been due to the fact that health information technology tends to be costly to implement. In

*All Correspondence should be sent to this address 
America, where the use of health technology is more pronounced, adoption of such innovation has consequently led to an increase in overall healthcare costs which were pegged at US\$2.5 trillion in 2009 (Hobson, 2009). The introduction of new technological innovation in health institutions may consequently result in business process re-engineering which would require a lot of time and resources in order for the new systems to be implemented successfully (Zigiaris, 2000). The stunted development of health institutions has also been attributed to poor planning, poor management and general lack of co-operation by policy implementers (Medical Research Council, 2012).

The growth and development of the South African Health service delivery has also been negatively affected by the HIV and AIDS pandemic within the country (Zupane, 2011). As a result government has had to then prioritize and increase expenditure on HIV medication to R1.6 billion which may have reduced expenditure on service delivery enhancements consequently (Smith, 2012).

However, although South Africa's health service delivery system is still relatively poor when compared to health services in most developed countries, the South African government should be commended for its efforts in helping to enhance the service experience. On the $6^{\text {th }}$ of November 2012, an academy was launched in South Africa to equip health workers in managerial positions with better skills needed to manage their health institutions well and improve service delivery (Khopotso, 2012). The skills program will go a long way in improving the service delivery in health institutions particularly state-owned hospitals which are usually overwhelmed by the large volume of patients.

Poor service delivery is increasingly becoming common in public health institutions as they have become "underresourced and oversubscribed" (Pallot, 2010). As this is the case, managing public health institutions should be a priority for all stakeholders particularly the government and will require a huge investment in technological innovations in order to improve service delivery. Improving service delivery may also help to reduce the reliance that the South African population has on private hospitals for better service delivery as they are relatively more expensive and beyond the reach of many, bearing in mind that over $80 \%$ of South Africa's population does not have private medical insurance (Baleta, 2012).

Adopting technology has several positive implications for South African health institutions. Zupane (2011) also believes that adopting technological innovation in health institutions is likely to enhance the efficiency and effectiveness of the operations of health institutions. Introducing new technological innovation will also go a long way in helping health institutions to appraise and monitor performance of hospital staff, communicate effectively with customers using CRM systems as well as reduce redundancy in the storage of patient information by making use of cloud-service technologies. An improvement in service experience will therefore go a long way in fostering patient satisfaction and increasing consumer loyalty over time.

The researchers decided to conduct the study in Johannesburg as it is a populous city with an estimated population of roughly 3.8million (SouthAfrica.info, 2012). There is an urgent need to address service delivery quality in Johannesburg health institutions as it has dropped over the years. Public healthcare in South Africa, which caters for $80 \%$ of the population, has been continuously strained over the years (BBCNews, 2011) and this research presents some practical solutions that can be implemented to mitigate the problems associated with poor health service delivery. Johannesburg is also the most suitable city to conduct the study as it is known to be a "vibrant and diverse cosmopolitan city," (Murray, 2010). As this is the case, data collected to determine the perception of patients on the adoption of technology in health institutions may represent a wider Johannesburg demographic which may make the findings applicable in other similar provinces in South Africa and beyond.

\subsection{Problem statement}

Not much research had been carried out regarding the practicality of making use of technological innovation to enhance service delivery in South African health institutions. A number of authors, however, noted how public service organizations are associated with bureaucracy and inefficiency due to "excessive politicization and lack of accountability and representation," (Ayee, 2005). Authors such as (Zupane, 2011), also merely highlighted the importance of service administration in enhancing service delivery without putting much emphasis on how technological innovation could be used to enhance this service experience. The government of South Africa has however remained committed in investing in ICT in order to make it more accessible to at least $80 \%$ of South Africans by 2020 and this may potentially materialize more especially as technological devices become more affordable and accessible in developing and emerging economies (Herald, 2012).

The wide adoption of mobile technology has made it more viable for the adoption of technology in health institutions which is why some analyst predict that "the key to better healthcare might be in our pockets, and it is not our wallets," (Kozelka, 2013). Health institutions should then consider making use of innovations such as CRM systems, 
cloud computing and web applications as these tools can go a long way in enhancing service delivery in the healthcare industry.

\subsection{Objective of the study}

The objective of this study is therefore to assess the feasibility of adopting technological innovations such as CRMs, web applications and cloud computing in order to enhance service delivery in selected Johannesburg Health institutions by assessing the perception of patients on technological innovation.

The research question for this study has therefore been stated below:

Should selected Johannesburg health institutions adopt technological innovations in order to enhance service delivery and increase patient satisfaction?

\section{Literature Review}

$21^{\text {st }}$ century consumers have become more cautious of their role in the market and this has made them demand better service delivery when they interact with institutions (Zupane, 2011). In South Africa, service delivery is said to be influenced by social, economic, cultural, political, legislative technological and economic factors (Zupane, 2011). As this is the case, it becomes imperative for institutions to consider factoring these elements when creating service offerings for their intended market in order to stay relevant and competitive,

Cognitive Dissonance often results when a strongly held expectation is disconfirmed and this may have longlasting implications on any given institution (Hasan \& Nasreen, 2012). It is essential for health institutions to avoid situations where patients are dissatisfied as this may have the potential to tarnish the image of the particular health institution in the long-run. Kessler (2009) noted that "satisfaction has business implications for healthcare providers" which is why it is particularly important for health institutions to continuously work towards enhancing service delivery in order to satisfy consumers and obtain a competitive advantage.

Technology, most recently has grown to become one of the major elements influencing businesses in both developing and developed countries (Ernst Young, 2012). According to (Intergate Immigration, 2012), about 11\% of South Africa's population uses their hand-held devices to access the internet and they are over 29million South Africans who are currently using mobile phones. The growing accessibility of technology can therefore help to facilitate the quick adoption of innovations in health institutions.

The researchers focused on three technologies that can be adopted by selected health institutions in Johannesburg to enhance service delivery and these technologies are CRM systems, web applications and cloud computing technology.

\subsection{Consumer Relationship Management}

CRMs are an important technology which gives an enterprise approach to developing knowledge about customer behavior and preferences and developing strategies that can help to build the relationship between firms and their markets (Parvatiyar \& Sheth, 2001). Both public and private hospitals should make use of CRMs in order to be better able to identify and meet the individual needs of patients profitably. This will consequently lead to patient loyalty as it creates a platform for them to develop a relationship with the particular health institution. Adopting CRMs in South African health institutions may however be fairly challenging as they are quite expensive to implement and maintain (Ranjbarian, et al., 2010).

\subsection{Cloud Computing}

Cloud computing allows information to be available on demand "at scale in a multi-tenant environment" by ensuring that IT resources and service are abstracted from the underlying infrastructure (Gupta, 2011). Using cloud computing services will go a long way in ensuring that efficiency is increased in the health institution as it becomes easier to create and update patient information. Gupta (2011) Suggests that workflows for most hospitals consists of paper-records, fragmented and inefficient systems and duplicate tests, and by adopting cloud technology in hospitals, this will be greatly be reduced. The $21^{\text {st }}$ century market place has been hit by information overload and cloud computing provides just the right solution to deal with the problem by bringing agility, elasticity and economic viability to the business environment (Winans \& Brown, 2008). 
Figure 1: Proposed Theoretical Model

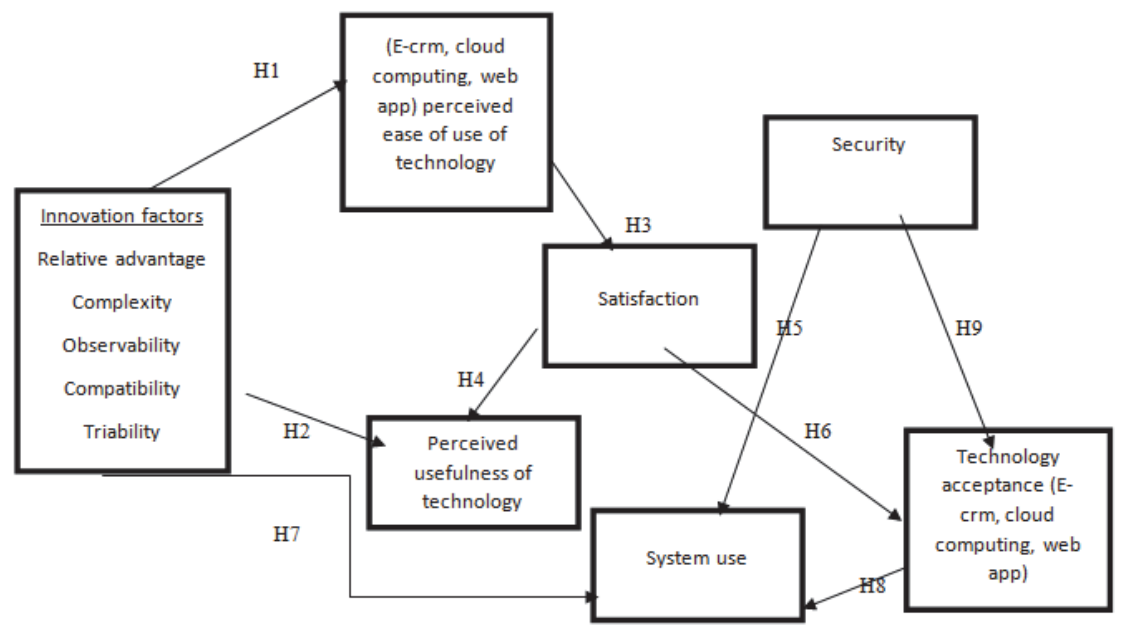

Source: (Ranjbarian, et al., 2010)

There are various factors that can help determine whether a particular technology can be adopted by a given market. Some of the factors include elements of the Diffusion of innovation theory by Rogers (1995) such as compatibility and level of complexity of the technological, accessibility and the relative advantage it presents to users. The elements of the TAM by Davis (1989) are also particularly important as they can be used to determine the feasibility of adopting an innovation based on the perceptions of the user. The researchers therefore created a modified version of the TAM which has been illustrated below.

Various hypotheses were therefore formulated based on the modified version of the TAM model above. Figure 1 shows the hypothesized relationships between the different variables.

$\mathrm{H1}$ : Innovation factors determine the ease of use of a particular technological innovation

H2: Innovation factors can determine perceived ease of use of a particular technological innovation such as ECRM, cloud computing and web applications

H3: Perceived ease of use of technological innovation determines satisfaction of customer

H4: Perceived usefulness of the technological innovation determines satisfaction of patients

H5: The level of security of the technological innovation ultimately determines the system usage

H6: Satisfaction determines level of technological innovation acceptance by patients

$\mathrm{H} 7$ : Innovation factors determines system use of technological innovation by patients

H8: Technological innovation acceptance determines system usage by patients

H9: Security of the technological innovation determines technological innovation acceptance by patients.

\section{Methodology}

\subsection{Research design}

Primary research was conducted by distributing a 5 point likert scale questionnaire to patients at Helen Josephs and Charles Maxeke Hospitals. Galpin (2013) highlighted the importance of making use of large sample sizes in order to detect small differences within a given sample. Raosoft statistical software was therefore used to determine the sample size for the research and after calculating, it was established that a total of 358 questionnaires needed to be distributed.

\subsection{Data Analysis}

SAS statistical software was used to analyze data gathered from questionnaires in order to critically evaluate patients' perceptions regarding the adoption of technological innovation in hospitals. Various statistical methods were used in order to compare and evaluate data collected and conclusions were then drawn from the data that had been gathered. 


\subsubsection{Reliability and Validity test}

After a preliminary pilot study was conducted to determine the levels of reliability of the questionnaire, it was observed that the scales used to conduct the study were reliable with the Cronbach alpha ranging between 0,744741 and 0.816041 . The results for each element have been provided in the table below:

Table 1: Reliability Test Cronbach-Alpha

\begin{tabular}{|l|c|}
\hline Variable & Cronbach-alpha value (a) \\
\hline Satisfaction & 0.783223 \\
\hline Perceived Usefulness & 0.756381 \\
\hline Innovation Factors & 0.749715 \\
\hline Technological Acceptance & 0.771153 \\
\hline System Usage & 0.763793 \\
\hline Perceived Ease of Use & 0.816041 \\
\hline Security & 0.744741 \\
\hline
\end{tabular}

From the table it can be noted that Security had the lowest level of reliability with a cronbach-alpha of 0.744741 whilst the Perceived Ease of Use variable had the highest cronbach-alpha of 0.816041.

\subsubsection{Linear Regression Analysis}

The researchers managed to determine the relationships between the independent and dependent variables of the model for the research by making of the regression analysis. This was essentially done to test the proposed hypothesis and these have been provided below.

\subsubsection{H1: Innovation factors determine the perceived ease of use of a particular technological innovation}

Table 2: Linear regression for innovation factors and its effect on perceived ease of use

\begin{tabular}{|c|c|c|c|}
\hline Root MSE & 0.59521 & R-Square & 0.2239 \\
\hline Dependent Mean & 3.47133 & Adj R-Sq & 0.2213 \\
\hline CoeffVar & 17.14653 & & \\
\hline
\end{tabular}

\begin{tabular}{|c|c|c|c|c|c|}
\hline \multicolumn{7}{|c|}{ Parameter Estimates } \\
\hline Variable & DF & $\begin{array}{c}\text { Parameter } \\
\text { Estimate }\end{array}$ & $\begin{array}{c}\text { Standard } \\
\text { Error }\end{array}$ & $\mathbf{t}$ Value & $\operatorname{Pr}>|\mathbf{t}|$ \\
\hline Intercept & 1 & 2.01772 & 0.16049 & 12.57 & $<.0001$ \\
\hline Innovation & 1 & 0.38013 & 0.04100 & 9.27 & $<.0001$ \\
\hline
\end{tabular}

From the table 2 above, the null hypothesis is rejected as the p-value is less than the $5 \%$ level of significance. This therefore implies that the researchers rejected the null hypothesis which states that Innovation factors determine the perceived ease of use of a particular technological innovation. (Lee, et al., 2011), also discovered the same relationship between the two variables.

\subsubsection{H2 : linear regression between innovation factors and perceived usefulness of a particular technology}

The linear regression seeks to test the relationship between innovation factors and perceived usefulness. The test therefore tries to establish whether innovation factors such as complexity, triability, observability and others affect perceived usefulness of a given technology. 
Table 3: Linear regression to determine effect of innovation factors on perceived usefulness

\begin{tabular}{|c|c|c|c|c|c|}
\hline \multicolumn{7}{|c|}{ Parameter Estimates } \\
\hline Variable & DF & $\begin{array}{c}\text { Parameter } \\
\text { Estimate }\end{array}$ & $\begin{array}{c}\text { Standard } \\
\text { Error }\end{array}$ & $\mathbf{t}$ Value & $\operatorname{Pr}>|\mathbf{t}|$ \\
\hline Intercept & 1 & 1.66829 & 0.13155 & 12.68 & $<.0001$ \\
\hline innovation & 1 & 0.50515 & 0.03360 & 15.03 & $<.0001$ \\
\hline
\end{tabular}

The Null hypothesis is rejected as the p-value 0.001 is $<0.005 \%$. This implies that innovation factors determine perceived usefulness. Results show that there is a positive relationship between innovation factors and perceived usefulness which suggests that it is essential for a technological innovation to be relatively less complex for it to be easily adopted by patients as it influences the level of perceived usefulness of the given technology.

\subsubsection{H3: linear regression between satisfaction and perceived ease of use}

This linear regression was aimed at determining whether perceived ease of use had an effect on satisfaction. The null and alternative hypothesis are given below:

Table 4: Linear regression between satisfaction and perceived ease of use

\begin{tabular}{|c|c|c|c|c|c|}
\hline \multicolumn{7}{|c|}{ Parameter Estimates } \\
\hline Variable & DF & $\begin{array}{c}\text { Parameter } \\
\text { Estimate }\end{array}$ & $\begin{array}{c}\text { Standard } \\
\text { Error }\end{array}$ & $\mathbf{t}$ Value & $\operatorname{Pr}>|\mathbf{t}|$ \\
\hline Intercept & 1 & 2.59162 & 0.12676 & 20.45 & $<.0001$ \\
\hline Perceived ease of use & 1 & 0.08842 & 0.03585 & 2.47 & 0.0142 \\
\hline
\end{tabular}

Based on the findings above it can therefore be noted that the null hypothesis as the $p$-value is $<0.0142$ which is less than the $5 \%$ level of significance. This implies that perceived ease of use does determine the levels of satisfaction of the user of the system ultimately. The finding also supports the study made by (Mahmood, et al., 2000) which also noted that perceived ease of use of a given technology has a positive relationship and determines levels of satisfaction.

\subsubsection{H4: Linear regression between satisfaction and perceived usefulness}

This hypothesis also seeks to determine the relationship between satisfaction and perceived usefulness by potential users of the system.

Table 5: Linear regression between satisfaction and perceived usefulness

\begin{tabular}{|c|c|c|c|c|c|}
\hline \multicolumn{7}{|c|}{ Parameter Estimates } \\
\hline Variable & DF & $\begin{array}{c}\text { Parameter } \\
\text { Estimate }\end{array}$ & $\begin{array}{c}\text { Standard } \\
\text { Error }\end{array}$ & $\mathbf{t}$ Value & $\operatorname{Pr}>|\mathbf{t}|$ \\
\hline Intercept & 1 & 2.21636 & 0.13236 & 16.75 & $<.0001$ \\
\hline Perceived Usefulness & 1 & 0.18950 & 0.03619 & 5.24 & $<.0001$ \\
\hline
\end{tabular}

Table 5 indicates that the $p$-value of the model is $<0.0001$ which is lower than the significance level of 0.05 . This means that the model is significant and a good fit for the data. The p-value is also significant for perceived usefulness variable hence the null hypotheses is rejected at the $5 \%$ level of significance and accept the alternative hypothesis. This then means that there is a positive relationship between perceived usefulness and satisfaction and this also reinforces the findings made by (Mahmood, et al., 2000) who also discovered that there is a positive relationship between the two variables.

\subsubsection{H5: Level of security determines system usage.}

The linear regression below seeks to determine the relationship between security and system usage as it had been suggested that the level of security of a particular technological innovation has an effect on the system usage. The null 
and alternative hypothesis are once again provided below:

Table 6: Level of security determines system usage.

\begin{tabular}{|c|c|c|c|c|c|}
\hline \multicolumn{7}{|c|}{ Parameter Estimates } \\
\hline Variable & DF & $\begin{array}{c}\text { Parameter } \\
\text { Estimate }\end{array}$ & $\begin{array}{c}\text { Standard } \\
\text { Error }\end{array}$ & $\mathrm{t}$ Value & $\operatorname{Pr}>|\mathbf{t}|$ \\
\hline Intercept & 1 & 2.00074 & 0.17995 & 11.12 & $<.0001$ \\
\hline Security & 1 & 0.27299 & 0.04438 & 6.15 & $<.0001$ \\
\hline
\end{tabular}

From table 6 above the P-value is $<0.001$ hence the null hypothesis is rejected as it is less than the $5 \%$ level of significance. Therefore it can be concluded that security ultimately affects system usage of the new technological innovation which can be a CRM or use of cloud services to store information on a virtual drive for future reference of patient files. The findings from the study also support by a similar study done by (Omary, et al., 2010) who also discovered that adoption of technological equipment by health institutions in developing countries is greatly affected by the security concerns of stakeholders involved.

\subsubsection{H6: Satisfaction determines level of technology acceptance by patients.}

The hypothesis seeks to determine whether satisfaction determines levels of technology adoption by patients.

Table 7: Satisfaction determines level of technology acceptance

\begin{tabular}{|c|c|c|c|c|c|}
\hline \multicolumn{7}{|c|}{ Parameter Estimates } \\
\hline Variable & DF & $\begin{array}{c}\text { Parameter } \\
\text { Estimate }\end{array}$ & $\begin{array}{c}\text { Standard } \\
\text { Error }\end{array}$ & $\mathrm{t}$ Value & $\operatorname{Pr}>|\mathbf{t}|$ \\
\hline Intercept & 1 & 1.86217 & 0.21849 & 8.52 & $<.0001$ \\
\hline Satisfaction & 1 & 0.39859 & 0.07460 & 5.34 & $<.0001$ \\
\hline
\end{tabular}

From the table 7 above, the null hypothesis is rejected as the p-value is less than the $5 \%$ level of significance. This therefore implies that satisfaction determines level of technological acceptance by patients.

\subsubsection{H7: Innovation factors determines system use of technological innovation by patients}

This hypothesis seeks to determine if there is no relationship between innovation factors and system usage.

Table 8: Linear regression to determine whether innovation factors influence system use

\begin{tabular}{|l|l|l|l|l|l|}
\hline \multicolumn{5}{|l|}{ Parameter Estimates } & Pr $>|\mathbf{t}|$ \\
\hline Variable & DF & $\begin{array}{l}\text { Parameter } \\
\text { Estimate }\end{array}$ & $\begin{array}{l}\text { Standard } \\
\text { Error }\end{array}$ & $\mathbf{t}$ Value & (n) \\
\hline Intercept & 1 & 1.94484 & 0.15434 & 12.60 & $<.0001$ \\
\hline Innovation & 1 & 0.29889 & 0.03943 & 7.58 & $<.0001$ \\
\hline
\end{tabular}

From the tables above, the $p$-value $<0.001$ hence the null hypothesis is rejected since the $p$-value is less than the $5 \%$ level of significance. Therefore innovation factors do affect system use.

\subsubsection{H8: Technological acceptance determines system use}

This hypothesis sought to determine if there is relationship between technological acceptance and system use. 
Table 9: Linear regression to determine whether innovation factors influence system use

\begin{tabular}{|c|c|c|c|c|c|}
\hline Variable & DF & $\begin{array}{c}\text { Parameter } \\
\text { Estimate }\end{array}$ & $\begin{array}{c}\text { Standard } \\
\text { Error }\end{array}$ & $\mathbf{t}$ Value & $\operatorname{Pr}>|\mathbf{t}|$ \\
\hline Intercept & 1 & 2.20407 & 0.18823 & 11.71 & $<.0001$ \\
\hline T acceptance & 1 & 0.29286 & 0.06130 & 4.78 & $<.0001$ \\
\hline
\end{tabular}

From the table 8 above, the p-value is less than the $5 \%$ level of significance hence the null hypotheses is rejected and accept the alternative hypothesis hence technological acceptance does influence system use.

\subsubsection{H9: Security determines level of Technological acceptance by patients}

The linear regression seeks to determine whether technological acceptance is influenced by security levels of a particular technological adoption.

Table 10: Linear regression to determine whether Security influences level of Technological acceptance

\begin{tabular}{|c|c|c|c|c|c|}
\hline \multicolumn{6}{|c|}{ Parameter Estimates } \\
\hline Variable & DF & $\begin{array}{c}\text { Parameter } \\
\text { Estimate }\end{array}$ & $\begin{array}{c}\text { Standard } \\
\text { Error }\end{array}$ & $\mathbf{t}$ Value & $\operatorname{Pr}>|\mathbf{t}|$ \\
\hline Intercept & 1 & 2.20360 & 0.16722 & 13.18 & $<.0001$ \\
\hline Security & 1 & 0.20439 & 0.04124 & 4.96 & $<.0001$ \\
\hline
\end{tabular}

From the data provided above it can be concluded that there security does influence the levels of technological acceptance as the p-value is less than the $5 \%$ level of significance and the null hypothesis is rejected.

\section{Main Findings}

The study established that for technological innovation to be adopted in public hospitals, elements from the TAM and Diffusion of Innovation theory models by Rogers (1995) and Davis (1989) should be highly considered. Hospital patients are likely to adopt new innovations if they perceive them to be easy to use and if they feel that they are likely to enhance their service experience in health institutions. Most patients are also highly likely to be more inclined to adopt a new technology if they understand the innovations functionality. Based on data collected from respondents in the two public health institutions, it was discovered that the general perceived usefulness of web applications, CRM system and cloud computing was quite high which may go a long way in motivating hospitals to consider adopting such innovations overtime.

Perceived usefulness has a positive effect on satisfaction which implies that patients are most likely to be satisfied and impressed with a particular innovation provided it has the necessary functionality to meet their needs

Innovation factors tend to influence satisfaction levels of patients. This therefore implies that complexity, observability and other sub-factors can have a major influence on satisfaction levels of patients which ultimately determines adoption and system usage of CRM technologies as well as web applications.

The study also discovered that security plays a major role in determining whether it is feasible to adopt certain technologies as patients tend to be reluctant to providing personal information and details to institutions. From the survey conducted it was therefore discovered that security may affect system usage and general acceptance of the technological innovation.

\section{Recommendations and Managerial Implications}

The research findings suggest that it is feasible for technological adoption to be made in selected Health institutions as patients generally have a positive perception on the use of technological innovations in hospitals. For health institutions to ensure that the implementation of these new technologies is done well, there is need to monitor potential users' attitudes as they ultimately affect level of acceptance and usage of the given innovations. Management will therefore be faced with the task of finding creative ways of introducing web-applications, cloud services and CRM systems to patients in order to increase the rates at which such innovations will be adopted. 
From the survey conducted it was discovered that many respondents are reluctant to having their personal information being stored by the health institutions which suggests that security should be prioritized in order to increase the likelihood of adoption of technological innovation in health institutions.

Adopting technological innovation in health institutions will be beneficial for health institutions as they can then create unique value propositions that are centered on providing convenience for patients. This will consequently help to foster competitive advantage levels of health institutions.

It is therefore strongly advisable for selected health institutions to consider adopting technological innovations on a large scale as it will help to better manage patient information making it easily accessible. Patient information can also be used to create unique value offerings through the use of CRMs for consumers which may go a long way in helping to increase patient satisfaction and loyalty.

\section{Limitations and Opportunities for Future Research}

The sample size of two hospitals is not a true representation of the actual number of health institutions around the city of Johannesburg which makes it difficult to assume that technological innovation can also be adopted in other areas around Johannesburg.

The researchers also focused primarily on the perception that patients have on technological innovations. Future research should therefore consider the feasibility of adopting technological innovation on staff members' as they are major stakeholders who influence the levels at which health institutions use such innovations

\section{Conclusion}

Therefore the general perceptions and attitudes of patients in selected health institutions around Johannesburg is favorable towards the adoption of technological innovation in order to enhance their service experiences when receiving treatment in health institutions.

Management of Johannesburg health institutions are therefore faced with the task of ensuring that the levels of complexity of innovations such as CRM systems and web-application are lowered in order to increase the level of satisfaction which ultimately has an impact on the general acceptance of these technologies by the public. Management should also prioritize security as it is a great concern to many patients and may potentially affect the rate of adoption and acceptance of technological innovation in the long-run.

In order to benefit substantially from the adoption of technological innovations in health institutions, management would need to prepare adequately by mobilizing various resources which will aid in facilitating and creating a conducive platform for patients to enhance their service experience in Johannesburg health institutions.

\section{References}

Adam Mahmood, M. O., Burn, J. M., Gemoets, L. A., \& Jacquez, C. (2000). Variables affecting information technology end-user satisfaction: a meta-analysis of the empirical literature. International Journal of Human-Computer Studies, 52(4), $751-771$.

Ayee, J. R. (2005). Public sector management in Africa. African development bank.

Baleta, A. (2012). South Africa rolls out pilot health insurance scheme. The Lancet, 379(9822), 1185.

BBCNews, 2011. BBCNews Africa. [Online] Available at: http://m.bbc.co.uk/news/world-africa-14504628

Cullinan, K., 2006. Health services in South Africa. Health-e News Service [Online] Available at: http://www.healthe.org.za/2006/01/29/health-services-in-south-africa-a-basic-introduction/

Galpin, J., (2013), Statistical Research Design and Analysis. Johannesburg: s.n.

Gupta, V., 2011. Cloud Computing in Healthcare. [Online] Available: http://www.healthcare.financialexpress.com/201109 litathealthcare04.shtml

Harrison, D. An overview of health and healthcare in South Africa 1994-2010: Priorities, progress and prospective new gains; 2009.

Hasan, U., \& Nasreen, D. R. (2012). Cognitive Dissonance and Its Impact On Consumer Buying Behaviour. IOSR Journal of Business and Management (IOSRJBM), 1(4), 07-12.Kessler P.D, M. D., 2009. International Journal Of Healthcare Quality Assurance. Does patient Satisfaction affect patient loyalty, pp. 266-273.

Herald, E. A., (2012), Leading IT summit to boost ICT sector in South Africa through improved broadband and infrastructure, s.l.: s.n.

Hobson, K., (2009) US News. [Online] Available: http://health.usnews.com/health-news/best-hospitals/articles/2009/07/10/cost-ofmedicine-are-high-tech-medical-devices-and-treatments-always-worth-it

IBM (2013) UNC Health Care Uses IBM Analytics to Manage Medical Data and Improve Patient Care Online Available: http://www03.ibm.com/press/us/en/pressrelease/42179.wss

Intergate Immigration, (2012) Intergate Immigration. [Online] Available at: http://www.intergate-immigration.com/blog/online-media-stats- 
for-south-africal

Kozelka, M., (2013) NBCNews. [Online] Available: http://rockcentre.nbcnews.com/news/2013/01/24/16677207-the-key-to-better-healthcare-may-already-be-in-your-pocket-and-its-not-your-wallet?lite

Lee, Y. H., Hsieh, Y. C., \& Hsu, C. N. (2011). Adding Innovation Diffusion Theory to the Technology Acceptance Model: Supporting Employees' Intentions to use E-Learning Systems. Educational Technology \& Society, 14(4), 124-137.

Medical Research Council (2012) eHealth Strategy South Africa. [Online] Available: http://www.doh.gov.za/docs/stratdocs/2012/eHealth_Strategy_South_Africa_2012-2016.pdf

Murray, M. J. (2010). Mbembe Achille and Nuttall Sarah, eds. Johannesburg: The Elusive Metropolis. Durham, NC: Duke University Press, 2009. Afterword by Arjun Appadurai and Carol A. Breckinridge. viiit 398 pp. Photographs. Notes. Bibliography. Index. Contributors List. \$99.95. Cloth. \$27.95 Paper. African Studies Review, 53(01), 153-155.

Omary, Z., Lupiana, D., Mtenzi, F., \& Wu, B. (2010). Analysis of the challenges affecting e-healthcare adoption in developing countries: A case of Tanzania. International Journal of Information Studies, 2(1), 38-50.

Pallot, P, (2010), The Telegraph. [Online] Available: http://www.telegraph.co.uk/health/expathealth/7733901/Expat-guide-to-South-Africahealthcare.html

Parvatiyar, A., \& Sheth, J. N. (2001). Customer relationship management: emerging practice, process, and discipline. Journal of Economic and Social research, 3(2), 1-34.

PricewaterhouseCoopers,(2011) PWC. [Online] Available at: http://www.pwc.com/en_US/us/financial-services/regulatoryservices/publications/assets/integrating-technology-into-your-compliance-program.pdf

Ramesh, R., (2011). The Guardian. [Online] Available: http://m.guardian.co.uk/society/2011aug/07/nhs-among-most-efficient-healthservices

Ranjbarian, D., Sanayei, A. \& Ansari, A., (2010). A Hybrid Technology Acceptance Approach for Using the CRM. International Journal of Information Science and Management, Special Issue.

Smith, D. (2012) Aids drugs increase South African life expectancy by five years [Online] Available: http://www.theguardian.com/world/2012/dec/03/aids-drugs-south-african-life

Söderlund, N., Schierhout, G., \& van den Heever, A. (1998). Private Health Care in South Africa: Technical Report to Chapter 13 of the 1998 SA Health Review. Health systems trust.

SouthAfrica.info, (2012), Health care in South Africa. [Online] Available at: http://www.southafrica.info/about/health/health.htm

Winans, T. \& Brown, J., (2008) Shaping Strategy in a World of Constant Disruption, Harvard Business Review. Motivating to Leverage Cloud and Service Grid Technologies: Pain Points that Cloud and Service Grids Address.

Zigiaris, S., 2000. INNOREGIO: dissemination of innovation and knowledge management techniques, s.l.: BPR Hellas SA.

Zupane P., (2011) Alternative Service Delivery models for the South African Public service for the year 2020. 